\title{
sciendo
}

Transport and Telecommunication, 2019, volume 20, no. 1, 74-81

Transport and Telecommunication Institute, Lomonosova 1, Riga, LV-1019, Latvia

DOI 10.2478/ttj-2019-0007

\section{STRATEGIC PLANNING OF CARS QUALITY IN OPERATION}

\author{
Dmitriy Aydarov ${ }^{1}$, Vladimir Kozlovskiy ${ }^{1}$, Vera Vakhnina ${ }^{2}$, \\ Tatyana Fomina ${ }^{1}$, Darya Ivanova ${ }^{1}$ \\ ${ }^{1}$ Samara State Technical University \\ Samara, Russia, 244 Molodogvardeyskaya str. \\ adv_tol@mail.ru \\ ${ }^{2}$ Togliatti State University \\ Togliatti, Russia, 14 Belorusskaya str. \\ V.Vahnina@tltsu.ru
}

\begin{abstract}
Attainment of high competitiveness indicators of products and services is a natural goal of each enterprise. This goal stems from the desire of stakeholders to ensure the continuous, long-term development of a company and the high performance of labour results. However, the market has leaders and outsiders for various reasons. And the outsiders can be decently prepared in organizational and technical terms. But something prevents them from successfully developing. In addition, a decision of methodological and analytical tasks is not cheap. Competent experts, relevant technical and technological support of the process, and, most importantly, the conditions for creative work are required. It is necessary effective management decisions based on the detailed analysis of warranty period of cars operation for solving main problems related to the quality and products competitiveness. Similar analytical activity is helping to improve the life circle processes, creates the opportunities to enhance customer satisfaction and sustainable development of automakers. The research has updated a problem of design and realization effective analytical tools for an appointment the quality objectives for the automotive corporations. This paper presents the results of development and implementation of the new approach to the strategic planning of products competitiveness and setting the quality objectives by the example of automotive industry.
\end{abstract}

Keywords: quality objectives, perceived quality, customer satisfaction, competitiveness, strategic planning, automotive industry

\section{Introduction}

In recent crisis years, many automakers have suffered because of a significant reduction in demand for products. Only a small part managed to maintain the previous sales volumes. Even fewer organizations were able to improve their positions.

As a rule, companies that are able to conduct analytical studies of the market from the point of view the main criteria of competitiveness are seeking growth. These companies correctly determine the target development trends and effectively implement the adopted management decisions (Kondo, 2001; Kumar et al., 2006; Kozlovskiy and Aydarov, 2017a).

Of course, the decision of methodological and analytical tasks is not cheap. Competent experts, relevant technical and technological support of the process, and, most importantly, the conditions for creative work are required. Unfortunately, there are not so many Russian organizations, where we can find analytical centres. Russian manufacturers cannot boast of leadership in many high-tech segments of production, focused on the mass customer, in particular in the automotive industry.

Many researchers are actively developing analytical areas of work (Shaygan et al., 2017; Kovács, 2017), continuously improving and honing tools for monitoring customer preferences. Leading companies understand that such studies most effectively provide the process of long-term development. The most important conclusions about market development forecasts are formed based on analysis of product competitiveness from the customers' point of view (Yu, 2007; Grigoroudis and Siskos, 2009; Klochkov and Gazizulina, 2016; Kozlovskiy and Aydarov, 2017b).

We should highlight the key role of analytical quality departments of leading companies that continuously accumulate all available information with the help of current information and technical tools. Analytical quality department of the modern company is an intellectual link that determines the target development trends of corporate competitiveness from a position of quality.

The following points should be noted, considering the experience of the Russian automotive industry connected with the setting of quality objectives. Until now, there is a lack of development the 
target competitiveness indicators based on a comprehensive data analysis on quality and reliability, as well as customer satisfaction in the different aspects of cars operation. In our opinion, this is a significant problem hampering the development of domestic automotive industry at the strategic level. The understanding level of customers' requests is insufficient for developing an effective strategy for design, production, and service.

It should be said that established quality indicators, such as reliability, maintainability, cost of car ownership, etc., added by new indicators. These include innovative and fashionable design, organicity and functionality of the location of tools for controlling the operating modes of onboard systems, etc. Although a few years ago, these indicators were not a priority, today they are significant factors in assessing the quality of new cars in operation.

The goal of this research is the development and implementation of the new approach to the strategic planning of products competitiveness and setting the quality objectives in the automotive industry.

\section{Analysis of Approaches to Strategic Planning of Cars Quality in Operation}

\subsection{Traditional approach to strategic planning of cars quality in operation}

A diagram reflecting the traditional approach to the strategic planning of quality objectives is shown in Figure 1 (for one of the largest Russian automakers). The main sense of this approach is to ensure a progressive reduction of the defectiveness level in the warranty period. This approach is characterized by a significant simplicity of the targets assignment and monitoring their achievement. At the same time, the issues related to quality assessment by customers, as well as the benchmarking studies results, do not fall within the automaker's attention. Separately, it should be noted that the targets indicators are presented in the absolute units of measurement (number of defects), using a guarantee database.

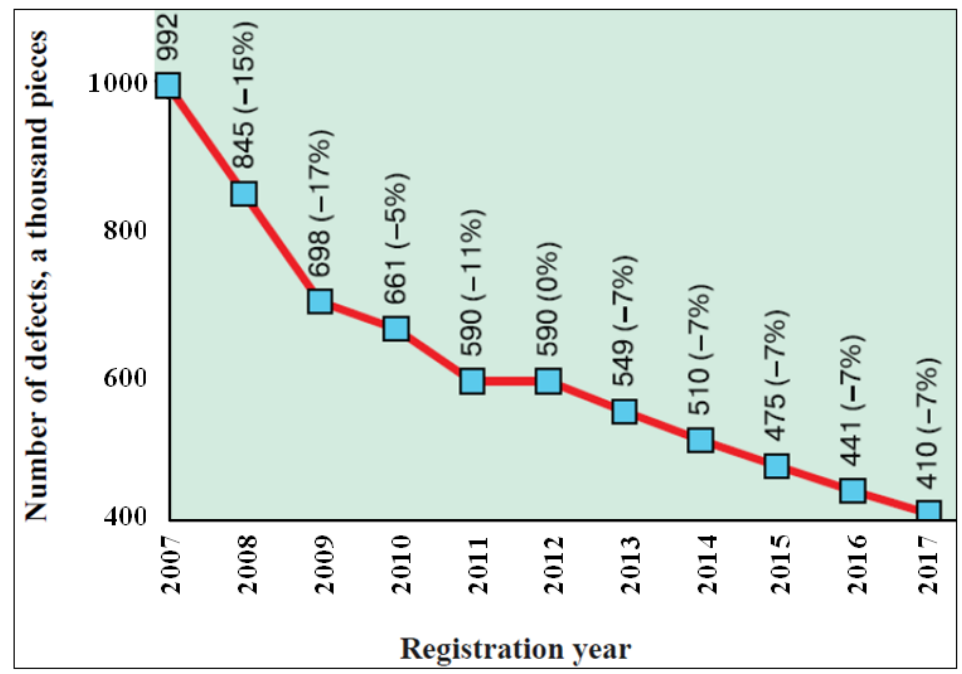

Figure 1. Traditional approach to strategic planning of cars quality in operation

However, the practice of a competitive market shows that the volumes of products sold can change from year to year (Aaker, 2009; Stylidis et al., 2014; Klochkov et al., 2017). In times of crisis, falling sales can be very significant, and if there are no sales, then there is nothing to service, and there are no defects. In this case, we assume that perspective goals can be achieved without changes in the company's work.

In addition, there are some specific areas of the car maintenance system. Leading automakers are only beginning to think about the need to introduce quality control in specific areas of work. And of course, today these areas of work are not covered by existing monitoring systems. Meanwhile, they are very significant from the economic point of view and significantly affect the business processes quality, both dealers, and the automaker. Specific areas of work include:

- return of defective products;

- elimination of some types of defects without the use of spare parts during the warranty period; 
- repeated repair to eliminate the same defects on the same cars;

- complex replacement of expensive components and aggregates on the warranty cars.

The lack of monitoring tools leads to additional costs for the automakers. Deviations in the work of dealers are the reason for the unreliable evaluation of the quality of new cars in operation and reduce the efficiency of production management (Kozlovskiy and Aydarov, 2017c).

Therefore, it is necessary to introduce target indicators of product quality, expressed in relative units and tied, for example, to the volume of output or sales. Then the risks associated with misinterpretation of the results of work in the field of quality are minimized.

\subsection{Approach to strategic planning of cars quality in operation using the defectiveness level}

At the international level (e.g. Thomas, 2006; Rai and Singh, 2009; Wu and Akbarov, 2011), one of the recognized indicators is the defectiveness level indicator presented for one thousand cars with a certain production date $(\mathrm{K} \%)$. Its use reduces the risks of incorrect conclusions about quality. This indicator reflects the number of failures (for the operation months group) per 1000 cars sold:

$$
K \%_{i}(M I S)=1000 \times \sum_{i=0}^{i=M I S} k_{i},
$$

where $k_{i}$ is a coefficient reflecting the ratio of the failures number to the cars sold number on the each of months included in the group of analysis, MIS (months in service) is the number of months between the date of sale and the date of setting the car for the warranty repair.

Consider Figure 2, which shows a diagram of automaker's quality objectives for 2009-2020.

However, in this case, there are limitations on ensuring the reliability of the analysed data, related to the requirement of car sales at least $40 \%$ of the output volume in the first month and then at least $10 \%$ monthly. During the realization of highlighted limits, the reliability of indicator reaches the level of $97 \%$ after six months of continuous quality analysis of the assigned group of cars.

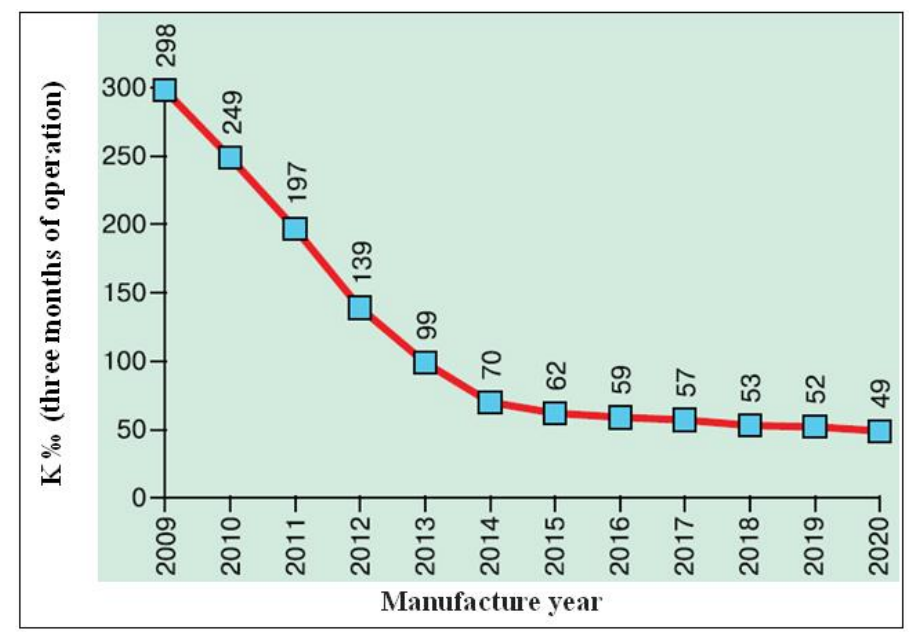

Figure 2. Approach to strategic planning of cars quality in operation using the defectiveness level indicator

This approach to strategic quality planning has the same drawbacks as the first. When assigning goals, there are no indicators reflecting customer satisfaction with the quality, as well as benchmarking results, and the only source of information is the warranty database for defects of cars under warranty operation.

\subsection{Differentiated approach to strategic planning of cars quality in operation}

An important task of work in the field of quality is the transformation of general goal of the company into the corresponding indicators of the divisions. To solve this issue, the overall indicator "Organization goals" it is required to stratify and form the groups of goals for the units (Ansoff, 1988; Garvin, 1988; Fleischmann et al., 2006; Blatstein, 2012).

Usually, for goals' assigning to organizational units, two algorithms are implemented:

- uniform reduction of the defectiveness level in all units; 
- reduction in defectiveness depending on the importance of the contribution of a particular unit to the formation of a generalized indicator of the actual level of product quality (differentiated approach).

Table 1 illustrates the stratification and translation of the overall goal into the respective objectives of the company's units, related to the first of considered approaches (Fig. 1).

Table 1. Transformation the quality objectives of the company to the objectives for units, based on the first approach

\begin{tabular}{|l|c|c|}
\hline \multicolumn{1}{|c|}{ Structural unit } & \multicolumn{1}{c|}{$\begin{array}{c}\text { Quality objectives } \\
\text { for the current year }\end{array}$} & $\begin{array}{c}\text { Quality objectives } \\
\text { for the next year (7\% improvement) }\end{array}$ \\
\hline \multicolumn{2}{|c|}{ Number of registered defects in operation } \\
\hline For the company as a whole & 590000 & 548700 \\
\hline Reserve & 9214 & 540131 \\
\hline Total & 580786 & 24389 \\
\hline Body assembly & 26225 & 105045 \\
\hline Mechanical assembly & 112951 & 132 \\
\hline Metallurgical production & 1217 & 30974 \\
\hline Engineering & 33305 & 1408 \\
\hline Experienced production & 1514 & 644 \\
\hline Manufacture of plastic products & 693 & 80 \\
\hline Press production & 86 & 141 \\
\hline $\begin{array}{l}\text { Manufacture of technological } \\
\text { equipment and tools }\end{array}$ & 151 & \\
\hline $\begin{array}{l}\text { Procurement department } \\
\text { of external components }\end{array}$ & 307358 & 285843 \\
\hline $\begin{array}{l}\text { Procurement department } \\
\text { of rubber and plastic products }\end{array}$ & 97286 & \\
\hline
\end{tabular}

Table 2 illustrates the stratification and translation of the overall goal into the respective objectives of the company's units, related to the second of considered approaches (Fig. 2).

Table 2. Transformation the quality objectives of the company to the objectives for units, based on the second approach

\begin{tabular}{|c|c|c|c|c|c|}
\hline \multirow{3}{*}{ Structural unit } & \multicolumn{5}{|c|}{ K\%o (according to the results of three months operation) } \\
\hline & \multicolumn{3}{|c|}{ Manufacture period } & \multirow[b]{2}{*}{ Average } & \multirow{2}{*}{$\begin{array}{c}\text { Target contribution } \\
\text { to the defectiveness } \\
\text { reduction } \\
\text { for the next year, \% }\end{array}$} \\
\hline & $\begin{array}{c}\text { January } \\
\text { of the } \\
\text { current year }\end{array}$ & $\begin{array}{c}\text { February } \\
\text { of the } \\
\text { current year }\end{array}$ & $\begin{array}{c}\text { March } \\
\text { of the } \\
\text { current year }\end{array}$ & & \\
\hline For the car models, in total & 214,15 & 224,04 & 250,13 & 229,44 & 8 \\
\hline Metallurgical production & 1,77 & 1,47 & 2,84 & 2,03 & 0,9 \\
\hline Mechanical assembly & 21,18 & 15,62 & 19,37 & 18,72 & 8,2 \\
\hline Body assembly & 8,37 & 10,27 & 18,99 & 12,54 & 5,5 \\
\hline Manufacture of plastic products & 0,89 & 1,48 & 1,84 & 1,40 & 0,6 \\
\hline Others & 4,42 & 4,41 & 3,85 & 4,23 & 1,8 \\
\hline Engineering & 1,76 & 3,23 & 3,17 & 2,72 & 1,2 \\
\hline Procurement departments & 175,76 & 187,56 & 200,07 & 187,80 & 8,9 \\
\hline
\end{tabular}

We can conclude that the differentiated approach is preferable since it takes into account the contribution of each structural unit to the overall target value.

\section{Research Results. New Approach to Strategic Planning of Cars Quality in Operation}

Despite the shortcomings of the traditional approaches to the quality objectives formation, many automakers still use them. Therefore, the development of an integrated approach to the quality objectives assignment is an actual task. This approach should meet modern methodological requirements and achievements and take into account a set of factors affecting the competitiveness of products from a quality standpoint.

Figure 3 presents the conception reflecting a new approach to the strategic planning of cars quality in operation. 
Concept structure includes all known sources of information (the upper level), in which the most fully accounted for data on the quality of cars in terms of defectiveness in operation, data on customer satisfaction, including the results of multi-brand studies, information reflecting the image component of quality through specialized mass media and Internet resources.

Let's move on to the middle level. Two problematic issues are solved here:

- adequate assessment of the different volumes of information to ensure the reliability of data used in planning quality indicators;

- combining and processing data and presenting the overall result as a target indicator in the framework of a unified methodology.

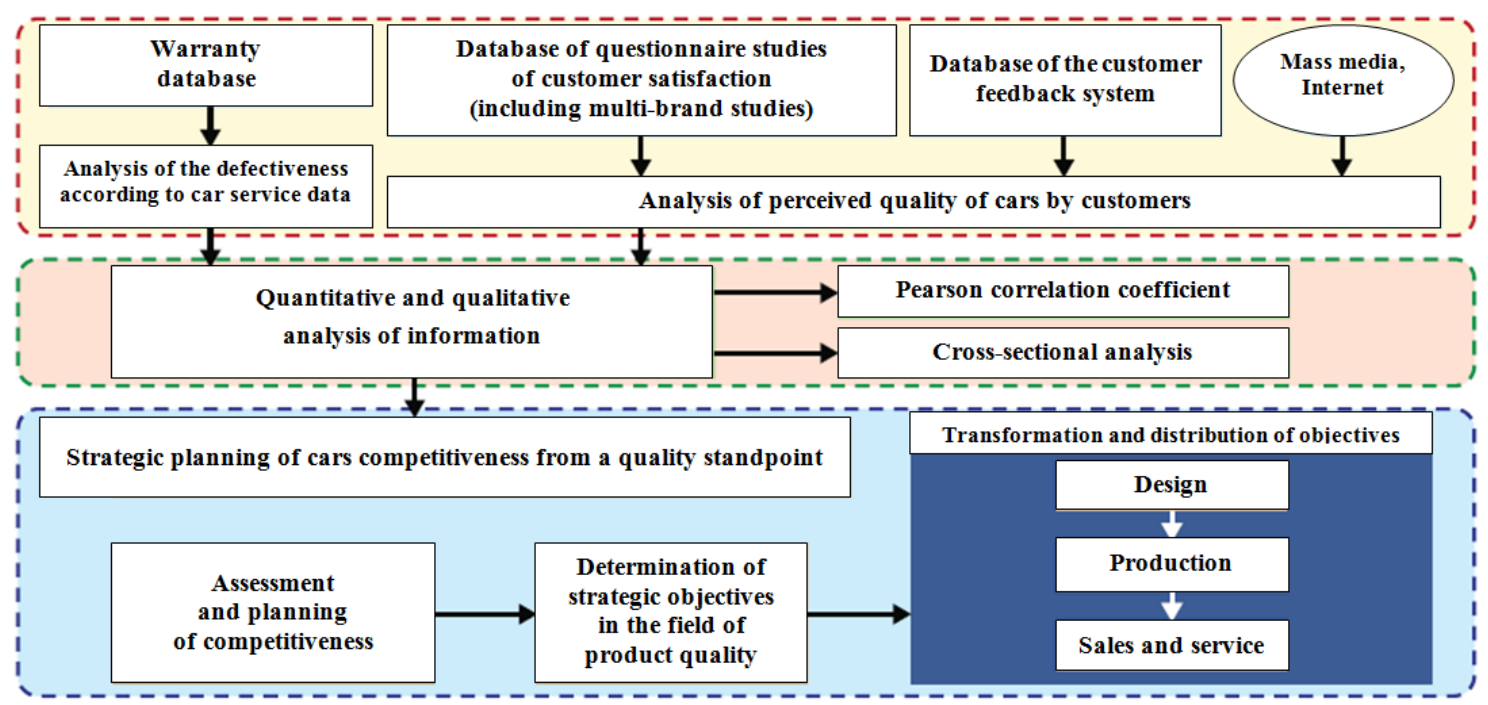

Figure 3. Conception of a new approach to strategic planning of cars quality in operation

To solve the first problem, we propose to use correlation analysis tools, for example, Pearson's criterion, which, as our experience shows, provides the best opportunities for analysing big electronic databases (Kozlovsky et al., 2016). Warranty database acts as the reference database. The main quantitative analysis of the correspondence of satisfaction databases, including multi-brand studies results, as well as customers feedback systems is carried out regarding warranty database. Assessment of compatibility with the warranty database is carried out by segments that reflect recorded defects at the car service enterprises. If the correlation coefficient is higher than 0.5 , then a positive conclusion is made about the reliability of information from different sources. Table 3 illustrates the correlation analysis results for three electronic databases, for cars of 2015, for the same automaker.

Table 3. Correlation analysis results of three electronic databases reflecting aspects of cars quality in operation

\begin{tabular}{|l|c|c|c|}
\hline \multirow{2}{*}{ Information databases } & \multicolumn{3}{|c|}{ Correlation coefficient, $\mathbf{R}$} \\
\cline { 2 - 4 } & $\begin{array}{c}\text { Satisfaction } \\
\text { databases }\end{array}$ & $\begin{array}{c}\text { Warranty } \\
\text { database }\end{array}$ & $\begin{array}{c}\text { Database of the customer } \\
\text { feedback system }\end{array}$ \\
\hline Warranty database & 0.718 & & \\
\hline $\begin{array}{l}\text { Database of the customer } \\
\text { feedback system }\end{array}$ & & 0.937 & \\
\hline Satisfaction databases & & & 0.821 \\
\hline
\end{tabular}

Today the greatest competitive advantage can be achieved through comprehensive studies of perceived quality (Jarzemskis and Jarzemskiene, 2017; Homer, 2008; Wiedmann et al., 2011). In the conditions of permanent crisis, for the automotive companies, the tasks related to measuring the perceived quality of products and services by customers acquire strategic importance, along with issues of ensuring products reliability (Mitra and Golder, 2006; Petiot et al., 2009; Falk et al., 2017).

It should be noted that part of information about the perceived quality or information that forms an image from a quality standpoint presented in the text form. And this information cannot be translated into a quantitative assessment using the codifiers. Therefore, in addition to the correlation analysis, we propose to use the method of cross-sectional data analysis. The essence of this method is to compare information pre- 
ranked according to certain principles and received from different sources. If the ranked list of one source is consistent with the ranked lists of others, then we can conclude that for further research there is an acceptable level of consistency and reliability of information from different sources (Table 4).

Table 4. Cross-sectional analysis results about aspects of cars quality in operation

\begin{tabular}{|l|c|c|c|c|c|}
\hline \multirow{2}{*}{ Car system } & \multicolumn{3}{|c|}{$\begin{array}{c}\text { Position of the car system } \\
\text { in the ranked list of problems }\end{array}$} & \multicolumn{2}{c|}{$\begin{array}{c}\text { Mentioning of problems } \\
\text { in information sources }\end{array}$} \\
\cline { 2 - 6 } & $\begin{array}{c}\text { Warranty } \\
\text { database }\end{array}$ & $\begin{array}{c}\text { Satisfaction } \\
\text { databases }\end{array}$ & $\begin{array}{c}\text { Database of the customer } \\
\text { feedback system }\end{array}$ & Mass media & Internet \\
\hline Electrical equipment system & 1 & 1 & 1 & + & + \\
\hline Internal combustion engine & 2 & 4 & 2 & + & + \\
\hline Body & 4 & 2 & 3 & + & + \\
\hline Suspension system & 3 & 5 & 4 & + & + \\
\hline Gearbox & 5 & 3 & 5 & - & + \\
\hline
\end{tabular}

Data analysis of Table 3 and Table 4 allows us to make a conclusion about an acceptable level of correspondence of information bases to each other.

To solve the second problem is to create a system of indicators reflecting different aspects of quality, but having the same physical meaning. Taking into account the perspectivity of the indicator $\mathrm{K} \%$, it is possible to develop two additional criteria for assessing the perceived quality of cars in operation:

- $\mathrm{E}_{1} \%$ - the level of customer complaints taking into account all aspects of perceived quality;

- $\mathrm{E}_{2} \%$ - the level of customer claims to the quality of products.

$\mathrm{E}_{1} \%$ can be calculated based on the analysis of questionnaires studies results, including multibrand. $E_{2} \%$ can be calculated based on the analysis of the customer feedback system. These criteria, complementing each other, enrich the understanding of customer desires. They combine into the overall indicator $\mathrm{E} \%$, reflecting the level of customer problems and complaints.

The number of customer complaints (satisfaction) for a group of months of analysis per 1000 cars sold is calculated by the formula

$$
E \% o_{i}(M I S)=1000 \times \sum_{i=0}^{i=M I S} e_{i},
$$

where $e_{i}$ is a coefficient reflecting the ratio of the complaints number to the cars sold number on the each of months included in the group of analysis, MIS (months in service) is the number of months between the date of sale and the date of setting the car for the warranty repair.

In this way, an information quality assessment system developed at the middle level. A system includes correlation (quantitative) and cross-sectional (qualitative) analysis. In addition, the criteria system reflects different aspects of cars quality in operation (defectiveness, satisfaction).

Results of the process "Strategic planning of cars competitiveness from a quality standpoint" (the lower level) presented in the form of a diagram reflecting the goals of the automaker (Fig. 4).

Calculation of the indicators $\mathrm{K} \%$ and $\mathrm{E} \%$ is carried out independently, using formulas 1 and 2. Calculation of the indicator $\mathrm{K} \%$ is carried out based on the results of data processing on the failures of cars in operation, through an information system linking the car service enterprises and the automaker. Calculation of the indicator E\%o is carried out based on the results of processing the questionnaires reflecting the customer satisfaction with the quality of cars in operation. These two databases are combined to determine the correlation of individual areas reflecting failures fixed at the car service enterprises. Such data is present in the first database, and also in the second database as a separate block of complaints. If the correlation coefficient is higher than 0.5 (Table 3), then the indicators $\mathrm{K} \%$ and E\%o can be combined at the corresponding diagrams. Thus, the ordinate represents the number of complaints, and the abscissa represents the corresponding number of registered defects (Fig. 4).

In the diagram presented, there is no distribution of the company's goals by years. This aspect defines the development strategy in the field of competitiveness from the position of quality. The automaker will have to independently determine the time it takes to achieve the best quality indicators on the market. But competitors do not stand still. And this fact also must be taken into account. 


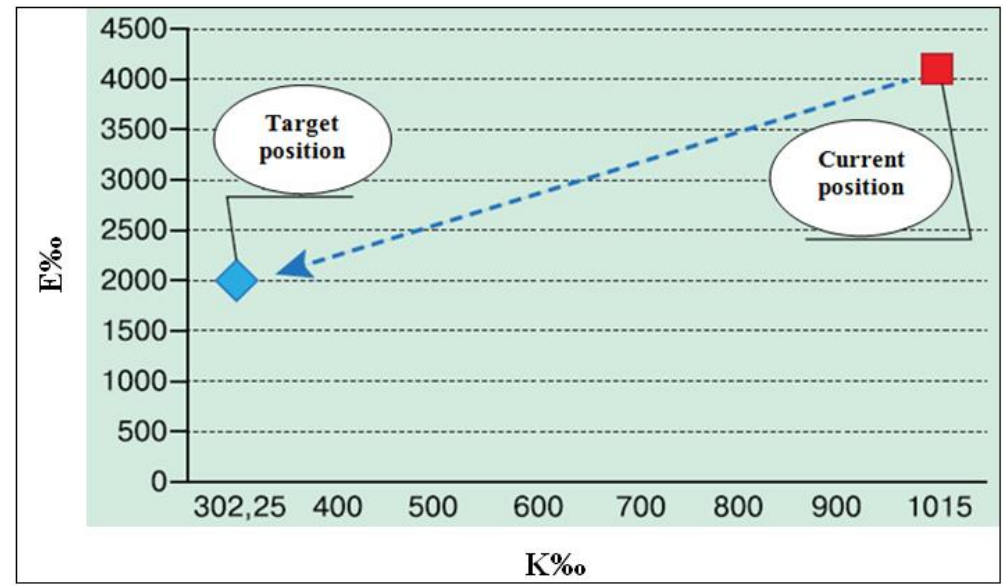

Figure 4. Perspective approach to strategic planning of cars quality in operation

The process of transforming the company's goal into the structural units indicators is somewhat harder, unlike traditional approaches. The main idea still based on the differentiated contribution of the units. But now, along with the defectiveness level, the criterion "Perceived quality of cars by customers" falls within the range of the criteria considered. Therefore, differentiation is carried out not only taking into account the defectiveness level, but also the contribution of a particular unit to the overall satisfaction assessment.

\section{Conclusions}

When assessing competitiveness in the segment of mass high-tech products, the criterion reflecting the price-quality ratio is still topical. Because of on the market there are many competing automakers, quality is the dominant factor of product competitiveness (including from the point of customer assessment view). In these conditions, traditional approaches to strategic quality planning are unacceptable.

Authors propose a new approach to the strategic planning of cars quality in operation, which takes into account the target indicators that are core in forming the competitiveness of automakers' products. In the proposed approach to product quality planning, along with the generally accepted indicator of the defectiveness level $(\mathrm{K} \%$ ) , the assessment of perceived quality of cars in operation by customers (E\%) is also taken into account. The quality planning when introducing new indicators E\%o is changing: now the automaker sets the quality objectives for the units not only in terms of progressive reduction of the defectiveness level but also in the form of significant reduction of customer complaints. The target position is determined by the best market practice in the field of quality, based on the analysis of benchmarking studies results.

In aggregate, we note the key results of the research:

- A common platform proposed for the process of developing and monitoring the quality objectives of automakers. The new approach to the strategic planning of products competitiveness and setting the quality objectives responds to current and future trends in the automotive industry.

- Platform usage in the high-tech industries practice (e.g. automotive and telecommunications) provides opportunities for improvement of the quality management systems and aims to improve the customer satisfaction by the perceived quality and product competitiveness.

- Further extension of the proposed approach is to deepen the detail level of the issues related to the transition from global quality objectives to single indicators of defects and costs to predict the achievability of the target indices.

\section{References}

1. Aaker, D.A. (2009) Managing Brand Equity. New York: Simon and Schuster.

2. Ansoff, H.I. (1988) The new corporate strategy. New York: John Wiley and Sons.

3. Blatstein, I.M. (2012) Strategic planning: predicting or shaping the future? Organization Development Journal, 30(2), 31-38. 
4. Falk, B., Stylidis, K., Wickman, C., Söderberg, R., and Schmitt, R. (2017) Shifting paradigm: Towards a comprehensive understanding of quality. In: Proceedings of the 21st International Conference on Engineering Design (ICED 17), 255-264.

5. Fleischmann, B., Ferber, S., and Henrich, P. (2006) Strategic Planning of BMW's Global Production Network. Interfaces, 36(3), 194-208.

6. Garvin, D.A. (1988) Managing quality: the strategic and competitive edge. New York: Free Press.

7. Grigoroudis, E., and Siskos, Y. (2009) Customer Satisfaction Evaluation. Oklahoma: Springer.

8. Homer, P.M. (2008) Perceived quality and image: When all is not "rosy". Journal of Business Research, 61(7), 715-723.

9. Jarzemskis, A., and Jarzemskiene, I. (2017) Evolution of Traveller Experience Quality Perception in European Level Policy Documents and the Case Study for Siauliai. Transport and Telecommunication, 18(3), 220-230.

10. Klochkov, Y., and Gazizulina A. (2016) Application of the Method of Performance Evaluation of the Production Process Design Using Associative Design. Key Engineering Materials, 684, 448-452.

11. Klochkov, Y., Papic, L., and Butkevich, R. (2017) Development of the Standardization System in an Organization. International Journal of Reliability, Quality and Safety Engineering, 24(6).

12. Kondo, Y. (2001) Customer satisfaction: How can I measure it? Total Quality Management, 12(7-8), 867-872.

13. Kovács, G. (2017) First Cost Calculation Methods for Road Freight Transport Activity. Transport and Telecommunication, 18(2), 107-117.

14. Kozlovskiy, V., and Aydarov, D. (2017a) Analytical Models of Mass Media as a Method of Quality Management in the Automotive Industry. Quality - Access to Success, 18(160), 83-87.

15. Kozlovskiy, V., and Aydarov, D. (2017b) System of Customer Satisfaction Monitoring by New Cars in View of Perceived Quality. Quality - Access to Success, 18(161), 54-58.

16. Kozlovskiy, V., and Aydarov, D. (2017c) Development of remote tools to assess the effectiveness and quality of car service enterprises work. International Journal for Quality Research, 11(3), 573586.

17. Kozlovsky, V., Klochkov, Y., Ostapenko, M., Ushanova, N., and Antipov, D. (2016) Conformity assessment of car quality databases exemplified on the case of the Russian car manufacturer "Auto VAZ". 5th International Conference on Reliability, Infocom Technologies and Optimization, ICRITO 2016, 57-60. DOI: 10.1109/ICRITO.2016.7784925

18. Kumar, M., Antony, J., Antony, F.J., and Madu, C.N. (2006) Winning customer loyalty in an automotive company through Six Sigma: a case study. Quality and Reliability Engineering International, 23(7), 849-866.

19. Mitra, D., and Golder, P.N. (2006) How Does Objective Quality Affect Perceived Quality? ShortTerm Effects, Long-Term Effects, and Asymmetries. Marketing Science, 25(3), 230-247.

20. Petiot, J.-F., Salvo, C., Hossoy, I., Papalambros, P.Y., and Gonzalez, R. (2009) A cross-cultural study of users' craftsmanship perceptions in vehicle interior design. International Journal of Product Development, 7(1/2), 28-46.

21. Rai, B.K., and Singh, N. (2009) Reliability Analysis and Prediction with Warranty Data: Issues, Strategies, and Methods. Boca Raton: CRC Press.

22. Shaygan, M., Mamdoohi, A., and Masoumi, H.E. (2017) Car Ownership Models in Iran: A Review of Methods and Determinants. Transport and Telecommunication, 18(1), 45-59.

23. Stylidis, K., Hoffenson, S., Wickman, C., Söderman, M., and Söderberg, R. (2014) Corporate and customer understanding of core values regarding perceived quality: Case studies on Volvo Car Group and Volvo Group Truck Technology. In: Proceedings of the 24th CIRP Design Conference, 171-176.

24. Thomas, M.U. (2006) Reliability and warranties: methods for product development and quality improvement. New York: Taylor \& Francis.

25. Wiedmann, K.-P., Hennigs, N., Schmidt, S., and Wuestefeld, T. (2011) Drivers and Outcomes of Brand Heritage: Consumers' Perception of Heritage Brands in the Automotive Industry. Journal of Marketing Theory and Practice, 19(2), 205-220.

26. Wu, S., and Akbarov, A. (2011) Support vector regression for warranty claim forecasting. European Journal of Operational Research, 213(1), 196-204.

27. Yu, S.-H. (2007) An Empirical Investigation on the Economic Consequences of Customer Satisfaction. Total Quality Management \& Business Excellence, 18(5), 555-569. 